\title{
Variation of Physico-Chemical and Textural Properties of Laboratory Prepared Red Mud Through Acid and Thermal Activations
}

\author{
Tsamo Cornelius ${ }^{1,2}$, Richard Kamga ${ }^{2}$ \\ ${ }^{1}$ Department of Chemistry, Higher Teachers' Training College, University of Maroua, Maroua, Cameroon \\ ${ }^{2}$ Laboratoire des Matériaux et Chimie Inorganique Industrielle, University of Ngaoundere, Ngaoundere, Cameroon
}

\section{Email address:}

tcornelius73@yahoo.com (T. Cornelius)

\section{To cite this article:}

Tsamo Cornelius, Richard Kamga. Variation of Physico-Chemical and Textural Properties of Laboratory Prepared Red Mud Through Acid and Thermal Activations. Advances in Materials. Vol. 6, No. 2, 2017, pp. 11-19. doi: 10.11648/j.am.20170602.12

Received: March 28, 2017; Accepted: April 18, 2017; Published: June 1, 2017

\begin{abstract}
Red mud prepared in the laboratory was activated using hydrochloric acid with concentrations from 2-4 mol/L, heat at $900^{\circ} \mathrm{C}$ and combined acid and heat at $900^{\circ} \mathrm{C}$, and the respective yields evaluated. The physico-chemical properties of these samples were determined using $\mathrm{pH}, \mathrm{EC}, \mathrm{XRF}$, XRD, SEM, TGA-DTA analyses and textural properties (isotherm type, BET surface area, pore size distribution, total pore volume, average pore size, external surface area, micropore volume, micropore area) determined by nitrogen gas adsorption-desorption. Acid activation reduces red mud quantity than by thermal means. Raw red mud showed a $\mathrm{pH}$ of 11.0 , EC of $2.50 \times 10^{9} \mu \mathrm{S} / \mathrm{cm}$, BET surface area of $13 \mathrm{~m}^{2} / \mathrm{g}$, total pore volume of 0.063 $\mathrm{cm}^{3} / \mathrm{g}$ with the major oxides being $\mathrm{Fe}_{2} \mathrm{O}_{3}, \mathrm{Al}_{2} \mathrm{O}_{3}, \mathrm{TiO}_{2}$ and $\mathrm{SiO}_{2}$. It contain mesopores $>$ macropores $>$ micropores. All these properties are improved variably by acid and thermal activation. Acid modification increase alumina content but decreases that of iron. Conversely, heat treatment increase iron content but reduces alumina content. Combined acid and heat treated red mud shows high thermal stability than untreated and acid treated red muds. These results show that possible different applications of red mud can be achieved depending on modification conditions.
\end{abstract}

Keywords: Bauxite, Red Mud, Activation, Minim-Martap, Properties

\section{Introduction}

Red mud is the insoluble residue resulting from caustic alumina production via the Bayer process, often colloquially referred to as red mud or bauxite residue or Bayer process tailings [1-2]. About $90 \%$ of raw bauxite ore goes into the waste as alkaline red mud slurry during processing [3] as for every ton of alumina produced, between 1-2 tons (dry weight) are produced depending on the bauxite source and alumina extraction efficiency [4-5]. Globally, between 60 120 million tons are produced annually [6-7]. This may lead to serious pollution of the surrounding soil, air and groundwater due to its high $\mathrm{pH}$ (10-13) [8-9].

However, red mud contains a number of valuable metals and minerals from parent bauxite consisting of gibbsite $\mathrm{Al}(\mathrm{OH})_{3}$, diaspore $(\mathrm{AlO}(\mathrm{OH}))$, hematite $\left(\mathrm{Fe}_{2} \mathrm{O}_{3}\right)$, goethite $(\mathrm{FeO}(\mathrm{OH}))$ and those introduced during the Bayer process such as sodalite, cancrinite etc. [2, 7, 10]. The typical constituents of red mud ( $\%$ w/w) are: $\mathrm{Fe}_{2} \mathrm{O}_{3}(30-60 \%), \mathrm{Al}_{2} \mathrm{O}_{3}$ (10-20\%), $\mathrm{SiO}_{2}(3-5 \%), \mathrm{Na}_{2} \mathrm{O}(2-10 \%), \mathrm{CaO}(2-8 \%), \mathrm{TiO}_{2}$ (trace-10\%) [11-12]. In general, red mud is a very fine material in terms of particle size distribution, having an average particle size $<10 \mu \mathrm{m}$. Typical values would account for $90 \%$ volume below $75 \mu \mathrm{m}$. The specific surface area (BET) is a round $10-25 \mathrm{~m}^{2} / \mathrm{g}$. Red mud contains various particles with different size and shape. Some crystals can also be found in the sample. In addition, it also presents porous surface [10].

Due to the alkaline nature and the chemical and mineralogical species present in red mud, this solid waste causes a significant impact on the environment and proper disposal of waste red mud presents a huge challenge where alumina industries are installed. The disposal cost is high, accounting for about $5 \%$ of alumina production $[10,13]$. Up to now, red mud has found limited applications in brick, glass, aerated concrete block, road base material, filling 
material in mining and plastic, as adsorbent to adsorb heavy metal ions and nonmetallic ions from wastewater and soil and $\mathrm{SO}_{2}$ in the waste gas [7, 10]. Unfortunately, none of these applications has been economically applied on an industrial scale [10].

Because of the environmental impact of red mud and its enormous volume, its treatment to change the alkalinity is extremely urgent issues with the aim of converting the harmful red mud to useful products with improved properties for different small and industrial applications. Many physical, chemical and mechanical methods are available for the modification of structural, textural and surface properties of solids. They include: acid activation, heat treatment, pillaring, crushing etc. [14]. The appropriate method depends strongly on the conditions of the parameters, origin of the ore and subsequent use of treated material. Hydrochloric acid $(\mathrm{HCl})$ has been the most used acid in red mud activation with concentrations of up to $2 \mathrm{M}$. Sketchy results are reported on the behaviour of chemical composition (as oxides) of red mud resulting from different activation methods. Also very few studies report properties of red mud treated with combined acid and thermal treatment in particular and the physico-chemical and textural properties of red mud activated with varying concentration of $\mathrm{HCl}$ in general.

The characteristics of red mud depend on the bauxite source extraction efficiency and modification conditions [15]. Thus, in this work, red mud (RM) prepared from MinimMartap (Cameroon) bauxite in the laboratory was activated with $\mathrm{HCl}$ (concentrations 2.0- $4 \mathrm{~mol} / \mathrm{L})$, noted nRMA ( $\mathrm{n}=$ acid concentration used), combined acid and heat treatment at $900^{\circ} \mathrm{C}$, noted $\mathrm{RMAC}$ and calcination of raw red mud at $900^{\circ} \mathrm{C}$, noted RMC. The $\mathrm{pH}, \mathrm{EC}$ and oxide composition of RM, nRMA, RMAC and RMC samples as well as the XRD, SEM, TG-DTA and nitrogen gas adsorption-desorption (isotherm type, BET surface area, pore size distribution, total pore volume, average pore size, external surface area, micropore volume, micropore area) of RM, 2,25M RMA and RMAC samples were investigated. This project constitute the long-term objective on the utilization of red mud and further studies as published information on red mud is owner and/or refinery specific and not consistent in either form or content [16]. This because each refinery has unique operating details with respect to red mud technologies, management and engineering practices thus, placing a severe limitation on the ability to collect systematize and interrogate information on the process.

\section{Materials and Methods}

\subsection{Preparation of Red Mud}

Red mud used for this study was produced in our laboratory from bauxite collected at Minim-Martap deposit (bauxite exploitation is about to start at this site, with close to a billion tons of bauxite [17]). Accordingly, $20 \mathrm{~g}$ of finely crushed and grind bauxite (powder particles of diameter < $100 \mu \mathrm{m})$ were mix with $120 \mathrm{ml}$ solution of $3 \mathrm{M} \mathrm{NaOH}$ in an
Erlenmeyer flask and stirred (300tr/min) for 33 minutes. The reaction mixture was then heated at $87^{\circ} \mathrm{C}$ for 20 minutes, allowed to cool down and filtered. Red mud was collected on the filter paper washed several times with distilled water, dried at $100^{\circ} \mathrm{C}$ overnight and used for activation and characterization without further treatment.

\subsection{Activation}

Red mud was activated by acid, combined acid and thermal activation and by thermal means. For acid activation, $10 \mathrm{~g}$ of water-washed and dried red mud was boiled in $200 \mathrm{ml}$ of corresponding $\mathrm{HCl}$ concentration $(2 \mathrm{M}, 2,25 \mathrm{M}, 2,5 \mathrm{M}, 3 \mathrm{M}$, and $4 \mathrm{M}$ ) for 20 minutes. The acid slurry was then filtered on a Whatman filter paper $\mathrm{N}^{0} 1$ and the residue washed many times with distilled water to remove residual acid and soluble $\mathrm{Fe}$ and $\mathrm{Al}$ compounds. Finally, the residue from each acid concentration was dried at $40^{\circ} \mathrm{C}$ (to avoid degradation of structure), stored (referred as nRMA, $\mathrm{n}=$ acid concentration) and used for the experiments without further treatment. Thermal activation of acid-activated and caustic red mud samples was carried out by placing the acid pre-activated (2M) and untreated red mud samples in a mudfle furnace for calcination at $900^{\circ} \mathrm{C}$ in air for $4 \mathrm{~h}$ (referred as RMAC and $\mathrm{RMC}$ respectively). The temperature ramp rate of the furnace was set to $10^{\circ} \mathrm{C} / \mathrm{min}$. The resultant powder solid samples were then allowed to cool down overnight in the furnace, recovered, stored and used without further treatment. The yield from each method of activation was evaluated.

\subsection{Determination of Physico-Chemical Properties of Red Mud}

The $\mathrm{pH}$ and electrical conductivity (EC) of all the samples (RM, nRMA, RMAC and RMC) were measured using a Hach HQ 40D multi $\mathrm{pH}$ meter within two decimal places. Also, the quantitative elemental composition (expressed as oxide) of all these red mud samples was determined by XRay Fluorescence (XRF) while the mineralogy of the raw red mud (RM), 2.25M acid activated (RMA) and combined acid and heat activated samples (RMAC) was determined by Xray Diffraction (XRD) using a Brucker D2 phaser in Bragg Brentano geometry with a Lynxeye detector using $\mathrm{Cu}-\mathrm{K} \alpha$ radiation at $30 \mathrm{kV}$ and $10 \mathrm{~mA}$. The diffraction peaks were then compared with those of red mud samples reported in literature for identification. The different phase transformations of RM, RMA and RMAC samples were investigated using the differential scanning calorimetrythermgravimetric (DSC-TGA) techniques on a perkin-Elmer apparatus while surface morphology of RM and RMA was determined by Scanning Electron Microscopy (SEM).

\subsection{Determination of Textural Properties of Red Mud}

These properties for the RM, RMA and RMAC samples were determined by gas adsorption using nitrogen adsorptiondesorption at the liquid nitrogen temperature $\left(-195,800^{\circ} \mathrm{C}\right)$ using a micromeritics tristar 3000 apparatus. The isotherm type was established by plotting quantity of gas adsorbed against 
experimental $\mathrm{P} / \mathrm{P}_{0}$ values. Samples isotherms obtained were compared with established models [18]. The BET plot was used to determine the total surface area, total pore volume and average pore size. The t-Plot was used to determine the external surface area, micropore volume and micropore area while the pore distribution was calculated using BJH (BarrettJoyner-Halenda) method [19-20].

\section{Results and Discussion}

\subsection{Yield of Red Mud After Activation}

Results are presented in Table 1 which shows that simple acid activation reduces considerably the quantity of red mud than thermal activation. The percentage of the reduction of red mud increases as the acid concentration increases. This shows that acid treatment induced the dissolution of the oxides of red mud namely: $\mathrm{Fe}_{2} \mathrm{O}_{3}, \mathrm{Al}_{2} \mathrm{O}_{3}$. This is due to the fact that acid activation often replaces exchangeable cations with $\mathrm{H}^{+}$ions and $\mathrm{Al}^{3+}$ and other cations escape out of the main structure. This increases the acidity of the material, along with the elimination of several mineral impurities and partial dissolution of the external layers [14]. Thermal treatment leads to little reduction of the initial amount of red mud. This could be attributed to dehydroxylation of adsorbed water at low temperature and dehydroxylation of hydroxides at higher temperature. It is also observed that acid-thermal treatment shows only $4 \%$ weight loss. This is probably due to the fact that this material contains only oxides. Of course most hydroxides have been dissolved during acid treatment.

Table 1. Quantity of red mud (\%) obtained from different methods of activation.

\begin{tabular}{|c|c|c|c|c|c|c|c|}
\hline & 2M RMA & 2.25M RMA & 2.5M RMA & 3M RMA & 4M RMA & 2M RMAC & RMC \\
\hline Yield (\%) & 65 & 60 & 35 & 27 & 23.5 & 96 & 85 \\
\hline
\end{tabular}

\subsection{Physico-Chemical Characteristics}

\subsection{1. $\mathrm{pH}$ and $\mathrm{EC}$}

From Table 2 it is seen that, a $\mathrm{pH}$ of 11.0 was found for the red mud prepared. Generally the $\mathrm{pH}$ of red mud varies from $10-13[5,21]$. This is due to the presence $\mathrm{OH}^{-}$resulting from high amount of $\mathrm{NaOH}$ used in the Bayer process [22]. Acid activation leads to a drop in $\mathrm{pH}$ but with increased acid concentration the $\mathrm{pH}$ increases. These variations are due to the different buffering and dissolution reactions [2, 16] that occur in red mud. It should be noted that red mud particles contain two types of hydroxyl groups; free hydroxide ions $(\mathrm{OH}-)$ and ionized surface hydroxyl groups (S-O-). Initially red mud particles consume $\mathrm{H}^{+}$without a change in $\mathrm{pH}$ due to the presence of free hydroxide ions $(\mathrm{OH}-)$ reacting with protons $\left(\mathrm{OH}^{-}+\mathrm{H}^{+} \rightarrow \mathrm{H}_{2} \mathrm{O}\right)$ more readily than the ionized surface hydroxyl groups. When all the free hydroxide ions are consumed (at neutral $\mathrm{pH}$ ) and protons added to the slurry, they are then consumed by surface hydroxyl groups $\left(\mathrm{S}^{-} \mathrm{O}^{-}+\right.$ $\mathrm{H}^{+} \rightarrow \mathrm{S}-\mathrm{OH}, \mathrm{S}-\mathrm{OH}+\mathrm{H}^{+} \rightarrow \mathrm{S}-\mathrm{OH}^{2+}$ ), causing a drop in the $\mathrm{pH}$ [23].

Our untreated red mud had an electrical conductivity (EC) of $2.5 \times 10^{9} \mu \mathrm{S} / \mathrm{cm}$ (Table 2). This value falls within the range of EC usually reported for red mud, (1.4-28.4) x $10^{9}$ $\mu \mathrm{S} / \mathrm{cm}$ [24]. This low EC value of our caustic red mud indicates low mobility of different ions within the red mud, thus, showing the compact nature of the residue. In the absence of detailed solution data, it is the only feasible quantity to measure total cation and anion concentrations and to estimate ionic strength. In red mud, ionic strength determines the double-layer thickness of charged particles and consequently the physical behavior such as dispersion and coagulation. The $\mathrm{EC}$ is due to high $\mathrm{Na}^{+}$concentrations in solution and in the solid phases. Calcium, magnesium and other cations do not contribute significantly to the $\mathrm{EC}$ as their concentrations are negligible in solution at $\mathrm{pH}$ above 10 [2]. Furthermore, the total amount of $\mathrm{CaO}$ and $\mathrm{MgO}$ is lower than $1 \%$ in our sample. The drop in EC values from $2.5 \times 10^{9}$ $\mu \mathrm{S} / \mathrm{cm}$ in $\mathrm{RM}$ to $1432 \mu \mathrm{S} / \mathrm{cm}$ in $2 \mathrm{M}$ RMA, $1410 \mu \mathrm{S} / \mathrm{cm}$ in 2.25M RMA, $542 \mu \mathrm{S} / \mathrm{cm}$ in $\mathrm{RMC}$ and $16.7 \mu \mathrm{S} / \mathrm{cm}$ in $2 \mathrm{M}$ RMAC is expected. This results from the fact that in caustic red mud, there are still several impurities and many free hydroxyl ions and sodium ions giving high EC, but when red mud is acid treated; the acid removes most of the impurities and these mobile ions $\left(\mathrm{Na}^{+}\right)$, giving rise to a more compact structure. But it is noticed that EC increases again, from 1410 $\mu \mathrm{S} / \mathrm{cm}$ in $2.25 \mathrm{M}$ RMA to $2.28 \times 10^{9} \mu \mathrm{S} / \mathrm{cm}$ in $2.5 \mathrm{M}$ RMA followed by a drop again. According to Palmer et al. [21], this increase indicates the increase in soluble salt content.

Table 2. $p H$ and EC of red mud different samples.

\begin{tabular}{|c|c|c|c|c|c|c|c|c|}
\hline & $\mathbf{R M}$ & 2M RMA & 2.25M RMA & 2.5M RMA & 3M RMA & 4M RMA & 2M RMAC & RMC \\
\hline $\mathrm{pH}$ & 11.00 & 2.28 & 2.12 & 2.15 & 2.49 & 2.76 & 5.25 & 10.37 \\
\hline $\mathrm{EC}(\mu \mathrm{S} / \mathrm{cm})$ & $2.5 \times 10^{9}$ & 1432 & 1410 & $2.28 \times 10^{9}$ & 978 & 681 & 16.7 & 542 \\
\hline
\end{tabular}

\subsubsection{Chemical Composition}

Table 3 present the oxide composition of untreated red mud (RM) obtained as well as the different samples of this red mud activated under different conditions. It can be seen from these results that: The types of elements present and the trends in content are similar to those reported by other authors [2, 16, 24-25 etc.] with the major oxides present being those of $\mathrm{Fe}, \mathrm{Al}, \mathrm{Ti}$ and $\mathrm{Si}$. Acid activation increases the quantities of oxides of $\mathrm{Al}, \mathrm{Si}$ and $\mathrm{Ti}$, with $\mathrm{Al}_{2} \mathrm{O}_{3}$ increasing from $13 \%$ in untreated red mud to $30.78 \%$ in $3 \mathrm{M} \mathrm{HCl}$ activated sample, $\mathrm{SiO}_{2}$ increasing from $2.76 \%$ in untreated red mud to $6.53 \%$ in $3 \mathrm{M} \mathrm{HCl}$ activated sample and $\mathrm{TiO}_{2}$ 
increasing from $3.76 \%$ in untreated red mud to $17.65 \%$ in $4 \mathrm{M}$ $\mathrm{HCl}$ activated sample. However, acid activation reduces significantly the quantity of $\mathrm{Fe}_{2} \mathrm{O}_{3}$ from $48.59 \%$ in untreated red mud to $20.34 \%$ in the $4 \mathrm{M} \mathrm{HCl}$ sample.

Heat treated red mud shows different behaviour with the quantity of $\mathrm{Fe}_{2} \mathrm{O}_{3}$ increasing from $48.59 \%$ in untreated red mud to $59.27 \%$ in the heat treated sample (RMC ) and $51.62 \%$ in the combined acid and heat treated sample (2M RMAC). Thus, the reduction in the yield of red mud observed in section 3.1 is principally due to the dissolution of $\mathrm{Fe}_{2} \mathrm{O}_{3} . \mathrm{Na}_{2} \mathrm{O}$ is almost completely eliminated through acid activation reducing it from $4.23 \%$ in untreated red mud to $0.06 \%$ in $2.5 \mathrm{M}$ RMA sample with the only increase $(5.85 \%)$ being in the RMC sample.

The increase in quantity of alumina, $\mathrm{SiO}_{2}$ and $\mathrm{TiO}_{2}$ and reduction of $\mathrm{Fe}_{2} \mathrm{O}_{3}$ with acid activation results from the fact that alumina, calcium oxide, silica, and rutile have high solubility in the extreme alkaline region. But hematite $\left(\mathrm{Fe}_{2} \mathrm{O}_{3}\right)$, on the other hand, has high solubility in acidic region but its solubility is very low in alkaline region [26]. To further elucidate this, some investigators have reported the removal of iron from bauxite using $\mathrm{HCl}$ by leaching. They found that iron could be completely removed by $\mathrm{HCl}$ leaching [27]. $\mathrm{TiO}_{2}$ could also have a high solubility in $\mathrm{HCl}$ but it takes a longer time at relatively high temperature. This has been illustrated in the study by Alafara et al. [28]. The almost complete elimination of $\mathrm{Na}_{2} \mathrm{O}$ is definitely due to its solubility in $\mathrm{HCl}$. The increased $\mathrm{Fe}_{2} \mathrm{O}_{3}$ quantity in calcined samples is due to the fact that minerals such as hematite, dicalcium silicate, perovskite, and $\mathrm{CaO}$ are not affected by temperature through the process contrary to $\mathrm{Al}$ and $\mathrm{Ca}$ bearing minerals. For example, gibbsite decomposes into $\mathrm{Al}_{2} \mathrm{O}_{3}$ and $\mathrm{H}_{2} \mathrm{O}$ from $300-550^{\circ} \mathrm{C}$; calcite to $\mathrm{CaO}$ and $\mathrm{CO}_{2}$ from $600-800^{\circ} \mathrm{C}$ on heating [7].

Table 3. Chemical composition of untreated and different activated samples of red mud in\% (w/w).

\begin{tabular}{|c|c|c|c|c|c|c|c|c|c|c|c|c|c|}
\hline & $\mathrm{SiO}_{2}$ & $\mathbf{A l}_{2} \mathbf{O}_{3}$ & $\mathrm{Fe}_{2} \mathrm{O}_{3}$ & $\mathrm{CaO}$ & MgO & $\mathrm{K}_{2} \mathrm{O}$ & $\mathrm{Na}_{2} \mathrm{O}$ & $\mathrm{SO}_{3}$ & $\mathrm{TiO}_{2}$ & $\mathrm{Mn}_{2} \mathrm{O}_{3}$ & $\mathbf{P}_{2} \mathbf{O}_{5}$ & LOI & Total \\
\hline $\mathrm{RM}$ & 2.76 & 16.41 & 48.59 & 0.53 & 0.08 & 0.07 & 4.23 & 0.12 & 3.76 & 0.03 & 0.11 & 9.02 & 82.33 \\
\hline 2M RMA & 3.44 & 24.77 & 44.90 & 0.39 & 0.10 & 0.07 & 0.36 & 0.07 & 9.99 & 0.06 & 0.21 & 16.18 & 100.54 \\
\hline 2.25M RMA & 2.21 & 16.10 & 52.29 & 0.05 & 0.06 & 0.04 & 0.18 & 0.06 & 5.79 & 0.03 & 0.14 & 15.46 & 92.41 \\
\hline 2.5M RMA & 2.99 & 21.86 & 41.36 & 0.32 & 0.09 & 0.06 & 0.06 & 0.06 & 10.04 & 0.06 & 0.20 & 22.05 & 99.15 \\
\hline 3M RMA & 6.53 & 30.78 & 27.11 & 0.34 & 0.13 & 0.12 & 0.19 & 0.11 & 10.58 & 0.08 & 0.16 & 23.04 & 99.17 \\
\hline 4M RMA & 5.79 & 29.57 & 20.34 & 0.98 & 0.13 & 0.16 & 0.24 & 0.07 & 17.65 & 0.18 & 0.18 & 23.31 & 98.55 \\
\hline 2M RMAC & 4.43 & 2.29 & 51.62 & 0.06 & 0.07 & 0.07 & 0.19 & 0.08 & 5.94 & 0.04 & 0.16 & 20.32 & 85.27 \\
\hline $\mathrm{RMC}$ & 2.87 & 18.01 & 59.27 & 0.36 & 0.08 & 0.04 & 5.85 & 0.14 & 4.95 & 0.04 & 0.13 & 7.60 & 99.34 \\
\hline
\end{tabular}

\subsubsection{Mineral Composition}

The XRD pattern of red mud (untreated) is shown in Figure 1a, which shows that Minim-Martap red mud is mainly composed of Hematite, goethite, quartz, gibbsite, calcite, diaspora and anatase. This composition is similar to the findings of [2]. It can also be seen from Figure $1 \mathrm{~b}$ that acid activation thus not modifies the mineral structure of red mud as it contains the same minerals with same intensities and $2 \varnothing$ values. However, heat treated sample Figure 1c shows the disappearance of aluminium (except goethite) and calcite minerals. This result confirms the increase in iron content of red mud when it was heat treated at $900^{\circ} \mathrm{C}$. The different peaks show high intensities. This is definitely due to increase in the purity of these different minerals resulting from the decomposition of gibbsite into $\mathrm{Al}_{2} \mathrm{O}_{3}$ and $\mathrm{H}_{2} \mathrm{O}$ and calcite to $\mathrm{CaO}$ and $\mathrm{CO}_{2}$. This XRD results confirm the XRF compositional variation of different red mud samples studied.

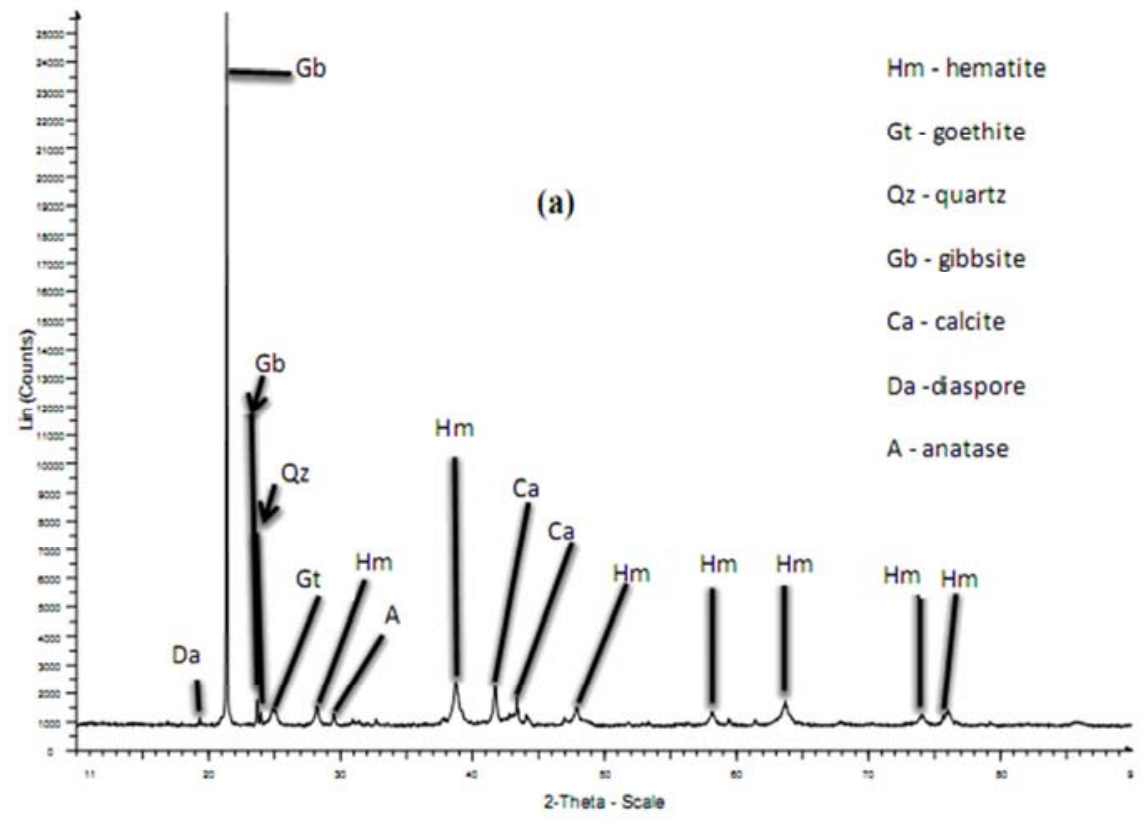



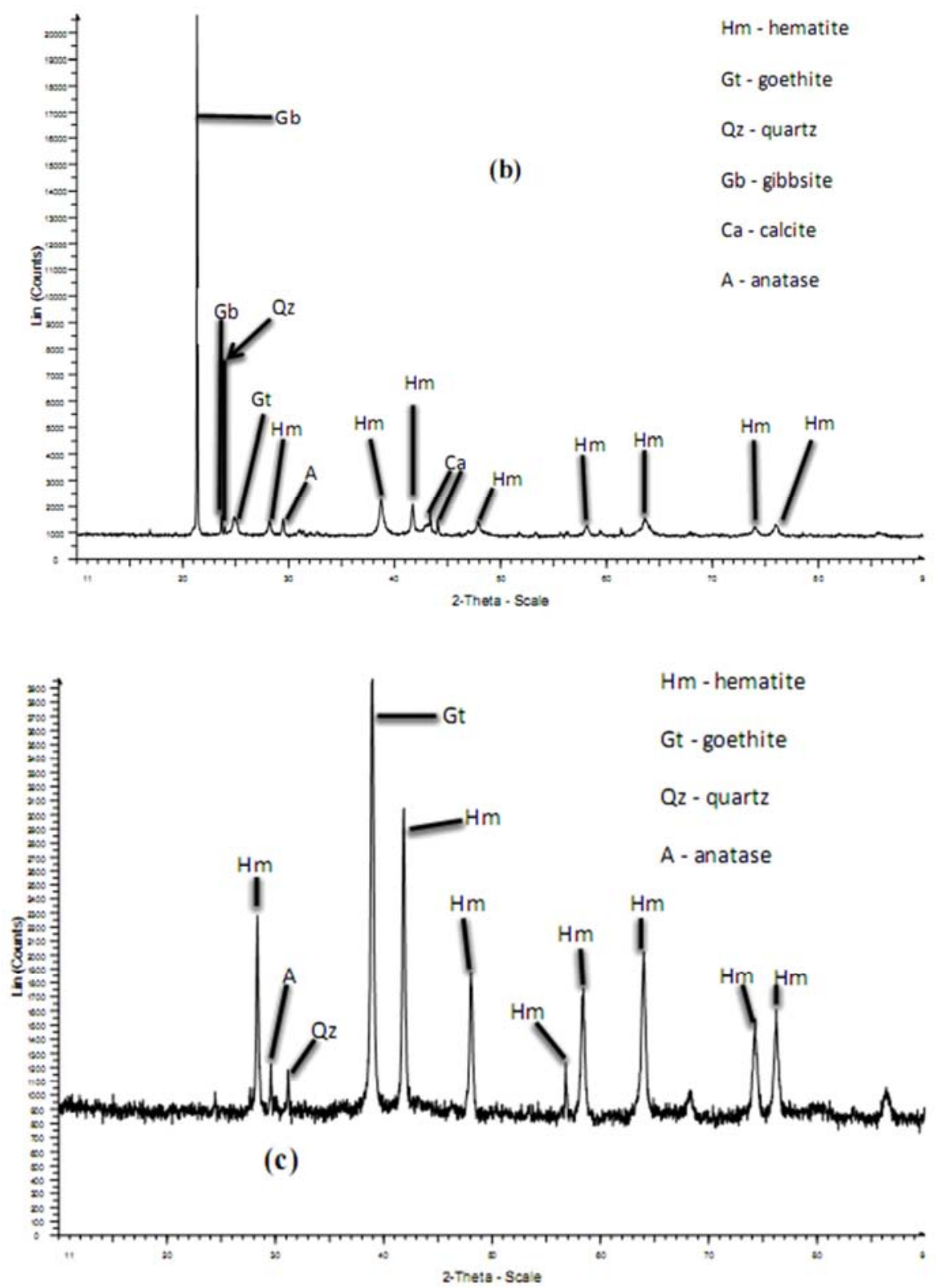

Figure 1. XRD patterns of a) untreated b) acid treated and c) combined acid and heat treated red muds.

\subsubsection{Surface Morphology (SEM)}

Figure 2 shows the SEM images of untreated red mud and acid activated sample. As seen from these images, the crude red mud particles are polycrystalline and poorly-crystallized or amorphous while there is a clear visual evidence, for the new pores and fine particles generated by strong acid treatment. The different porosity observed results from different physical and chemical processes mainly removal of acid soluble salts and dissolution of iron oxide.

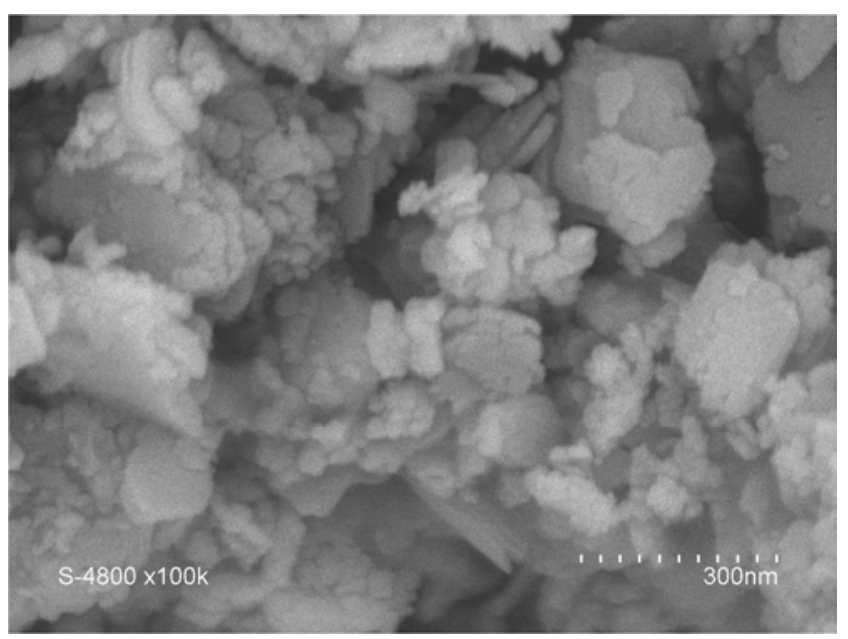

(a) 


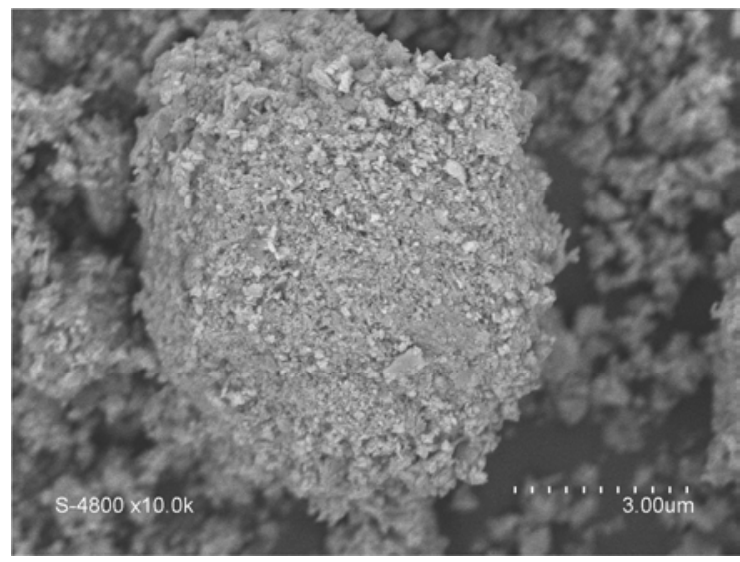

(b)

Figure 2. SEM images of (a) untreated red mud (b) acid activated red mud.

\subsubsection{Thermal Analysis}

Figure 3 shows the TGA-DTA plots of untreated (a), acid activated (b) and (c) combined acid and heat activated red mud samples. From these plots it can be seen that, the untreated (Figure 3a) and acid activated red muds (Figure 3b) show similar weight loss portions for TGA and similar phase transition for DTA. They all have three continuous weight loss portions.
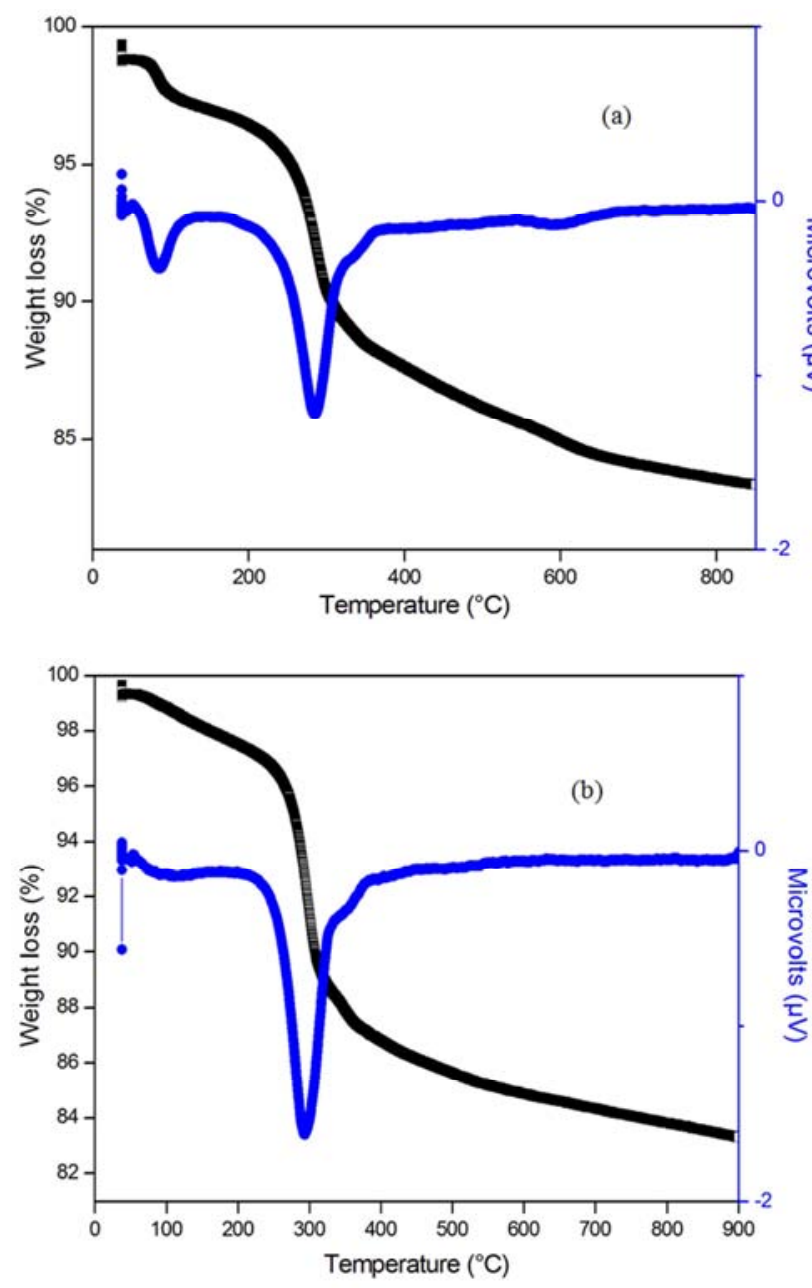

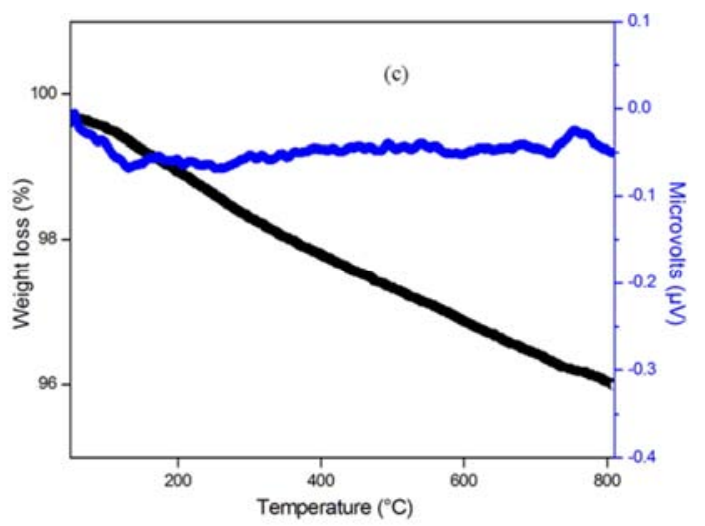

Figure 3. Thermo gravimetric (TG)-black line and Differential thermal (DT)-blue line analysis diagrams of (a) raw (b) acid activated and (c) combined acid and heat treated red muds.

From Figures $3 a$ and $3 b$, it can be seen the same quantity of material is being lost in the untreated and acid treated red muds from $150-350^{\circ} \mathrm{C}$ (about $10 \%$ ) and from $350-650^{\circ} \mathrm{C}$ (about 2\%). However, the acid treated red mud shows a higher weight lost from $90-150^{\circ} \mathrm{C}$ than untreated sample. This is probably due to increase in surface water during acid treatment. In each case the first weight lost is attributed to the evaporation of physically adsorbed water [29-30] while the rapid second and third weight losses corresponds to the loss of chemically adsorbed water due principally to the decomposition of gibbsite $\left(\mathrm{Al}(\mathrm{OH})_{3}\right)$ to alumina plus $\mathrm{H}_{2} \mathrm{O}$ and to decomposition of $\mathrm{CaCO}_{3}$ to $\mathrm{CaO}$ with the release of $\mathrm{CO}_{2}$, (1). Alumina then combines with the $\mathrm{CaO}$ to form tricalcium aluminate (2) or Gehlenite (3) in the $800-900^{\circ} \mathrm{C}$ temperature range $[7,29,31-32]$. This is why a constant mass is observed for the two samples as from $800^{\circ} \mathrm{C}$.

$$
\begin{gathered}
\mathrm{CaCO}_{3} \rightarrow \mathrm{CaO}+\mathrm{CO}_{2} \\
3 \mathrm{CaO}+\mathrm{Al}_{2} \mathrm{O}_{3} \rightarrow \mathrm{Ca}_{3} \mathrm{Al}_{2} \mathrm{O}_{6} \text { (tricalcium aluminate) } \\
4 \mathrm{CaO}+2 \mathrm{Al}_{2} \mathrm{O}_{3}+2 \mathrm{SiO}_{2} \rightarrow 2 \mathrm{Ca}_{2} \mathrm{Al}_{2} \mathrm{SiO}_{7} \text { (Gehlenite) }
\end{gathered}
$$

The DTA curves of untreated (Figure 3a,) and acid activated (Figure 3b) Minim-Martap red mud shows three endothermic peaks. The first with a maximum at $90^{\circ} \mathrm{C}$ corresponds to the desorption of physically adsorbed water as already stated. It is observed that the peak is more intense for raw red mud than acid treated red mud. This shows that the latter contain less water than the former. Thus acid treatment makes the surface of red mud more hydrophobic. The second peak (at $300^{\circ} \mathrm{C}$ ) of DTA curve corresponds to the phenomena described for TGA i.e. dehydration of gibbsite to alumina. The third peak at $600^{\circ} \mathrm{C}$ corresponds mostly to phase transition. At this temperature alumina combines with $\mathrm{CaO}$ to form aluminate or gehlemite as shown in (2) and (3). The DTA curves exhibited many incidents. This is a manifestation of many phase transitions that occur in the material. For example, the formation of $\mathrm{Ca}_{3} \mathrm{Al}_{2} \mathrm{O}_{6}, \mathrm{Ca}_{2} \mathrm{Al}_{2} \mathrm{SiO}_{7}, \mathrm{Fe}_{2} \mathrm{O}_{3}$ etc. For the combined acid and heat activated red mud (Figure $3 c$ ), there is only one weight loss portion which is rapid, continuous and very small (about 3\%). This 3\% loss can be 
attributed to the loss of physically adsorbed water and decomposition of $\mathrm{CaCO}_{3}$. Nonetheless, its DTA curve shows that is very stable on heating.

\subsection{Textural Properties}

\subsubsection{Type of Isotherm}

From the plots in Figure 4, it is evident that the isotherms of the three samples are of type IV isotherm model according to IUPAC classification [18, 33-34] characterized by monolayer formation (presence of micropores), presence of hysteresis ( $\mathrm{H} 1$ or $\mathrm{H} 2)$, indicating meso and macro pores for a and $b$ samples (characteristic of many oxide gels) and formation of few multilayer. Hysteresis is absent in sample $c$ as material is highly degraded.
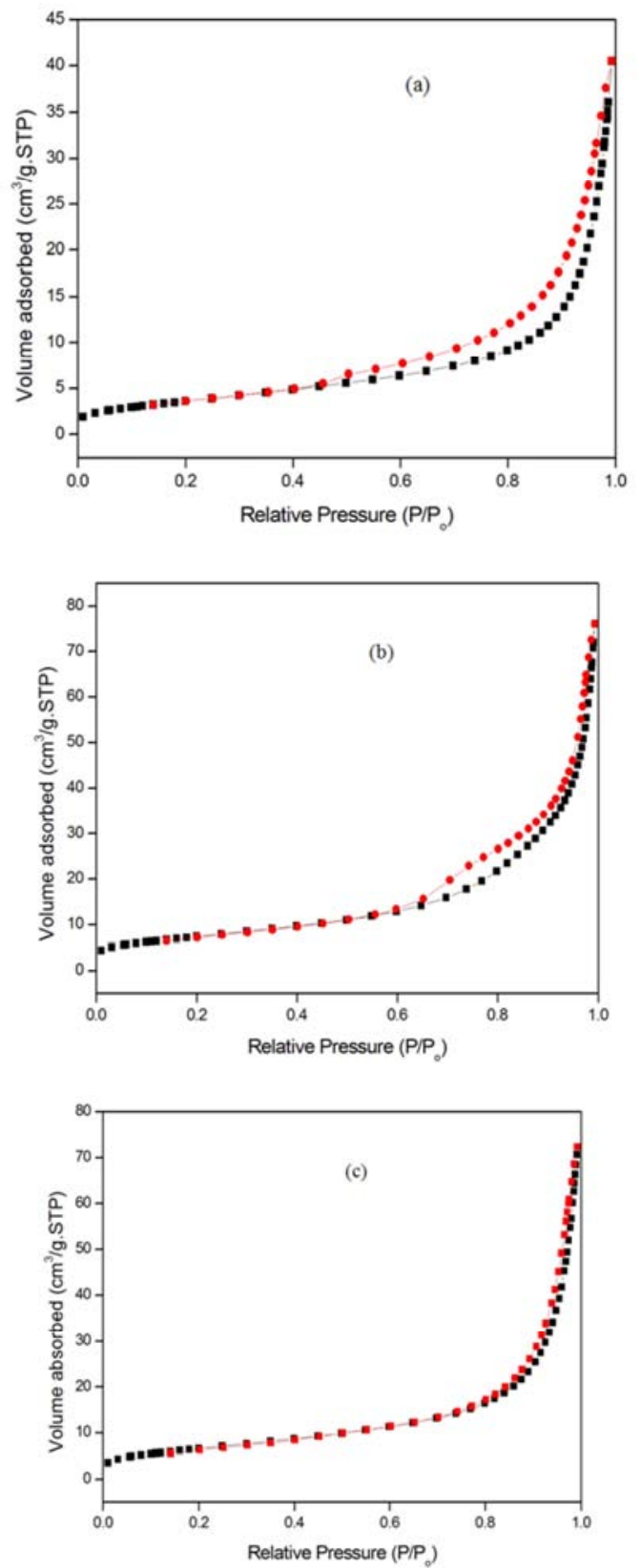

Figure 4. Isotherm plots for (a) untreated (b) acid activated and (c) combined acid and heat treated red muds.

\subsubsection{Porosity and Surface Area Analyses}

The BJH pore size distribution for untreated, acid activated and combined acid and heat treated Minim-Martap red mud is shown in Figure 5. The other textural properties determined notably, BET total surface area, external surface area, micropore area, micropore volume, diameter range, total pore volume and average pore width are presented in Table 4

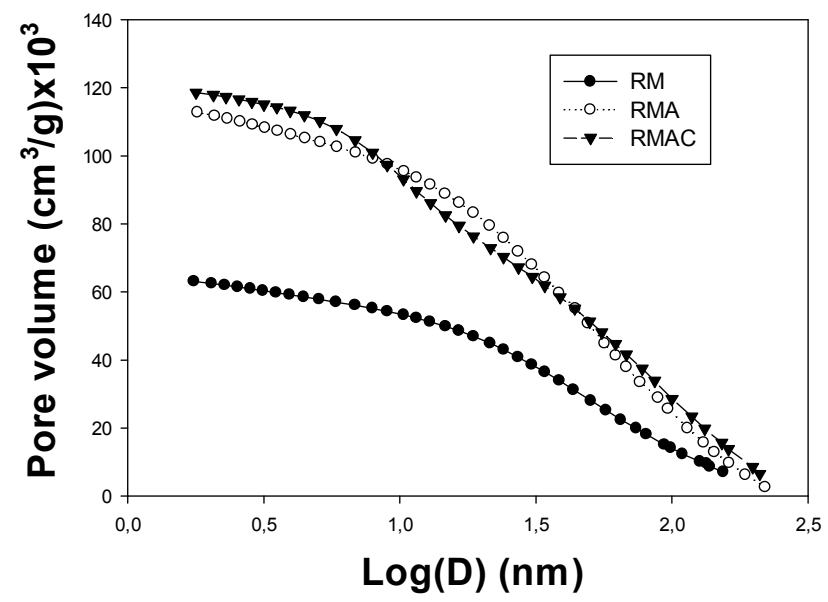

Figure 5. Pore size distribution curves of BJH adsorption for RM, RMA and RMAC Minim-Martap red mud samples. $D=$ Pore diameter.

The BJH curve Figure 5 shows that, red mud from MinimMartap bauxite contains: macropores (pores $>50 \mathrm{~nm}$ in diameter), mesopores pores (2-50 $\mathrm{nm}$ in diameter), and micropores (pores $<2 \mathrm{~nm}$ in diameter) [19]. From Figure 5 the calculated composition in percentage of the pore size distribution shows $66.67 \%$ of mesopores in RM, $67.50 \%$ in RMA and $67.50 \%$ in RMAC. It also shows $30.77 \%$ of maropores in RM, 30\% in RMA and 30\% in RMAC while micropore composition shows $2.56 \%$ in RM, $2.50 \%$ in RMA and $2.50 \%$ in RMAC. The mesopores are thus dominant in all the samples with a slight increase in the activated samples. Acid and thermal activation do not significantly alter the pore distribution but significantly leads to an increase in pore volume (Figure 5) and other textural properties (Table 4). BJH results confirm the results of isotherm type shown in Figure 4.

This dominance of mesopores and macropores to a lesser extent is also shown by higher values of external surface area; $14.88 \mathrm{~m}^{2} / \mathrm{g}$ and $25.21 \mathrm{~m}^{2} / \mathrm{g}$ respectively for raw and acid treated samples Table 4 . The corresponding BET total surface area is $13.1548 \mathrm{~m}^{2} / \mathrm{g}$ and $23.7978 \mathrm{~m}^{2} / \mathrm{g}$ for raw and the acid activated sample respectively. This analysis is based on the fact that external area is the area of those pores which are not micropores. Usually BET theory is applied to obtain the specific surface area of micro porous materials, although from a scientific point of view the assumptions made in the BET theory do not take into account micropore filling [20]. Mesopores, macropores and the outside surface is able to form a multiplayer, whereas micropores which have already been filled cannot contribute further to the adsorption process. The presence of micropores was confirmed using $y$ - 
intercept values from the t-plot (an intercept different from zero, indicate the presence of micropores [19]). These values in magnitude were: $0.595,0.510$ and $0.0784 \mathrm{~cm}^{3} / \mathrm{g}$ for the untreated, acid activated and heat activated red muds. This also confirms the BJH results.

Table 4. Summary of textural properties of raw and modified red mud samples.

\begin{tabular}{llll}
\hline & RM & 2.25M RMA & 2M RMAC \\
\hline BET surface area $\left(\mathrm{m}^{2} / \mathrm{g}\right)$ & 13.15 & 23.80 & 26.46 \\
External surface area $\left(\mathrm{m}^{2} / \mathrm{g}\right)$ & 14.88 & 25.21 & 26.05 \\
Micropore surface $\mathrm{area}\left(\mathrm{m}^{2} / \mathrm{g}\right)$ & $*$ & $*$ & 0.4166 \\
Micropore volume $\left(\mathrm{cm}^{3} / \mathrm{g}\right)$ & 0.000920 & 0.000789 & 0.000121 \\
Diameter range $(\mathrm{nm})$ & $1.7-300.0$ & $1.7-300.0$ & $1.7-300.0$ \\
Total pore volume $\left(\mathrm{cm}^{3} / \mathrm{g}\right)$ & 0.063 & 0.109 & 0.111 \\
Average pore width $(\mathrm{nm})$ & 19.04 & 18.38 & 16.85 \\
\hline
\end{tabular}

*The micropore area is not reported because the calculated external surface area is larger than the total surface area.

The porosity and surface area analyses show that the textural properties of raw and activated Minim-Martap red mud increases with the activation methods used. These increases are due the dissolution of some red mud components and elimination of several impurities. Huang et al. [35] and Wang et al. [36], reported similar trends in their studies when they activated red mud by acid, combined acid and heat, and heat treatment.

\section{Conclusions}

Results of this study shows that red mud can be modified depending on its subsequent use. The choice of the modification method however, depends strongly on the conditions of the parameter(s). For example modifying red mud with acid decreases its quantity more than when modified by heat treatment. However, acid modification increase alumina content but decreases that of iron. Conversely, heat treatment increase iron content but reduces alumina content. Under both conditions (acid and heat), the $\mathrm{Si}$ and $\mathrm{Ti}$ content show increases with significant increase when acid is used than the case of heat ( $\mathrm{Ti}$ increasing from about $3 \%$ to over $17 \%$ with $4 \mathrm{~mol} / \mathrm{L}$ acid). Also acid treatment does not modify the mineral composition of red mud but combined acid and heat treatment of red mud at $900^{\circ} \mathrm{C}$ significantly modifies the mineral composition with the elimination of most aluminum minerals and leaving a mainly iron mineral structure. The acid treated red mud and combined acid and heat treated red mud show increase porosity and surface area with combined acid and heat treated red mud having higher porosity and surface area. Modified and non-modified red mud contain mesopores $>$ macropores $>$ micropores. Combined acid and heat treated red mud shows high thermal stability than untreated and acid treated red muds which are thermally very not stable up to about $700^{\circ} \mathrm{C}$.

These results show that the harmful red mud can be converted to useful products with improved properties for different technological applications. This can contribute in an increase in utilization of red mud, thereby reducing its negative environmental impact and creating economic benefits.

\section{Competing Interests}

The authors declare that they have no competing interests.

\section{Acknowledgments}

This work was supported by the Department of Applied Chemistry, National Advanced School of Agro-Industrial Sciences, University of Ngaoundere, Cameroon.

\section{References}

[1] D. Tuazon and G. D. Corder, Life cycle assessment of seawater neutralised red mud for treatment of acid mine drainage, Resources, Conservation and Recycling, Vol. 52, pp. 1307-1314, 2008.

[2] M. Gräfe, G. Power and C. Klauber, Bauxite residue issues: III. Alkalinity and associated chemistry, Hydrometallurgy, Vol. 108, pp. 60-79, 2011.

[3] P. H. Huynh Ky, T. N. M. Tran and N. Le Truc, A study on activation process of red mud to use as an arsenic adsorbent

[4] S. Dursun, D. Guclu and M. Bas, Phosphate removal by using activated red mud from Seydisehir Aluminium Factory in Turkey, J. Int. Environmental Application \& Science, Vol. 1, no. $3 \& 4,98-106,2006$.

[5] S. Sushil and V. S. Batra, Catalytic applications of red mud, an aluminium industry waste: A review, Applied Catalysis B: Environmental, Vol. 81, pp. 64-77, 2008.

[6] P. Renfortha, W. M. Mayesb, A. P. Jarvisc, I. T. Burked, D. C. Manningc and K.. Gruize Science, Contaminant mobility and carbon sequestration downstream of the Ajka (Hungary) red mud spill: The effects of gypsum dosing. Sci. Total Environ, pp. 421-422, 253-259, 2012.

[7] W. Chuan-sheng and L. Dong-yan, Mineral Phase and Physical Properties of Red Mud Calcined at Different Temperatures, Journal of Nanomaterials, Volume 2012, Article ID 628592, 6 pages, 2012.

[8] H. J. Reeves, G. Wealthall and P. L. Younger, Advisory visit to the bauxite processing iailings dam near Ajka, Vesprem County, Western Hungary; Open Report OR/11/006; British Geological Survey: Keyworth, UK, 2011.

[9] A. Bhatnagar, V. J. P. Vilar, C. M. S. Botelho and R. A. R. Boaventura, A review of the use of red mud as adsorbent for the removal of toxic pollutants from water and wastewater, Environmental Technology, Vol. 32, no. 3, pp. 231-249, 2011

[10] S. Wang, H. M. Ang and M. O. Tadé, Review Novel applications of red mud as coagulant, adsorbent and catalyst for environmentally benign processes, Chemosphere, Vol. 72, pp. 1621-1635, 2008.

[11] D. Debadatta and K Pramanik, A Study on Chemical Leaching of Iron from Red mud using Sulphuric Acid, Res. J. Chem. Environ, Vol. 17, pp. 7, 2013. 
[12] B. E. H. Jones and R. J. Haynes, Bauxite Processing Residue: A Critical Review of Its Formation, Properties, Storage, and Revegetation, Critical Reviews in Environmental Science and Technology, Vol. 41, pp. 271-315, 2011.

[13] S. Kumar, R. Kumar and A. Bandopadhyay, Innovative methodologies for the utilization of wastes from metallurgical and allied industries. Resour. Conserv. Recycl., Vol. 48, pp. 301-314, 2006

[14] F. T. Ademiluyi and E. O. David-West, Effect of Chemical Activation on the Adsorption of Heavy Metals Using Activated Carbons from Waste Materials, Chemical Engineering Volume 2012, Article ID 674209, 5 pages, 2012.

[15] E. Lopez, B. Soto, M. Arias, A. Nunez, D. Rubinos and M. T. Barral, Adsorbent Properties of Red Mud and its use for Waste water Treatment, Water Research Vol. 32, no. 4, pp. 13141322, 1998.

[16] G. Power, M. Gräfe and C. Klauber, Bauxite residue issues: I. Current management, disposal and storage practices, Hydrometallurgy, Vol. 108, pp. 33-45, 2011.

[17] G. Komlóssy and W. B. Morrison, Comparison of bauxite, resources geo-economical considerations, Journal of Earth Sciences, Vol. 2, pp. 10-19, 2010.

[18] Quantachrome I n s t r u m e n t s, BET Surface Area Analyzer, Seminar and Practical Training Short Course, PPT, Rice University, USA, 2006.

[19] L. Emdadi, Characterizing Porous Materials and Powders, University of Maryland, USA, 2013.

[20] Quantachrome I n s t r u m e n t s, Physisorption Methods and Techniques, ppt, 1992.

[21] S. J. Palmer, R. L. Frost and T. M. Nguyen, Hydrotalcites and their role in coordination of anions in Bayer liquors: Anion binding in layered double hydroxides. Coordination Chemistry Reviews, Vol. 253, no. 1-2, pp. 250-267, 2009.

[22] C. Klauber, M. Grafe and G. Power, Review of Bauxite Residue "Re-use" Options, CSIRO Document DMR-3609, 2009.

[23] K. Zhang, H. Hu, L. Zhang and Q. Chen, Surface charge properties of red mud particles generated from Chinese diaspore bauxite, Trans. Nonferrous Met. Soc. China, Vol. 18, 2008.

[24] M. Grafe and G. Power, Review of Bauxite Residue Alkalinity and Associated Chemistry, CSIRO Document DMR-3610, 2009.

[25] K. Snars and R. J. Gilkes, Evaluation of bauxite residues (red muds) of different origins for environmental applications, Applied Clay Science, 46, pp. 13-20, 2009.
[26] A. S. Wagh, An overview of chemical processes to manufacture red mud construction products, International Seminar on Bauxite Residue (Red Mud), Vol. 36, no. 40, 235, 2011.

[27] G. Gulfen, M. Gulfen and A. O. Aydu, Dissolution kinetics of iron from diasporic bauxite in hydrochloric acid solution, Indian Journal of Chemical Technology Vol. 13, PP. 386-390, 2006.

[28] A. B. Alafara, A. A. Folahan, Emmanuela E. T. and B. B. Rafiu, Dissolution Kinetics and Leaching of Rutile Ore in Hydrochloric Acid, Journal of Minerals \& Materials Characterization \& Engineering, Vol. 8, no. 10, pp. 787-80, 2009.

[29] S. Agatzini-Leonardou, P. Oustadakis, P. E. Tsakiridis and Ch. Markopoulos, Titanium leaching from red mud by diluted sulfuric acid at atmospheric pressure, Journal of Hazardous Materials, Vol. 157, pp. 579-586, 2008.

[30] C. Klauber, N. Harwood, R. Hockridge and C. Middletonne, Proposed mechanism for the formation of dust horizons on bauxite residue disposal areas. In: de Young, D. H. (Ed.), Light Metals. TMS, New Orleans, pp. 19-24, 2008.

[31] D. Dodoo-Arhin, D. S. Konadu, E. Annan, F. P Buabeng, A. Yaya and B. Agyei-Tuffour, Fabrication and Characterisation of Ghanaian Bauxite Red Mud-Clay Composite Bricks for Construction Applications, American Journal of Materials Science, Vol. 3 no. 5, pp. 110-119, 2013.

[32] Y. Liu, C. Lin and Y. Wu, Characterization of redmud derived froma combined Bayer process and bauxite calcination method. J. Hazard. Mater. Vol. 146, no. 1-2, pp. 255-261, 2007b.

[33] A. V. Neimark, K. S. W. Sing and M. Thommes, Characterization of Solid Catalysts, Handbook of Heterogeneous Catalysis, 2nd Ed. Wiley-VCH Verlag GmbH \& Co. KGaA, Weinheim, 2008.

[34] K. S. W. Sing, D. H. Everett, R. A. Haul, W. L. Moscou, R. A. Pierotti, J. Rouquerol and T. Siemieniewska, Reporting physisorption data for Gas/Solid Systems with Special Reference to the Determination of Surface Area and Porosity (Recommendations 1984), Pure \& App!. Chem., Vol. 57, no. 4, pp. 603-619, 1985.

[35] W. Huang, S. Wang, Z. Zhu, L. Li, Yao X., V. Rudolph and F. Haghseresht, Phosphate removal from wastewater using red mud, Journal of Hazardous Materials, Vol. 158, pp. 35-42, 2008.

[36] S. Wang, Y. Boyjoo, A. Choueib and Z. H. Zhu, Removal of dyes from aqueous solution using fly ash and red mud, Water Research, Vol. 39, pp. 129-138, 2005. 